\title{
MULTIDISCIPLINARY SUSTAINABILITY - THE MULTIPLE PERSPECTIVES OF A SOCIAL ORGANIZATION
}

\author{
Leonilde Reis ${ }^{1}$ \\ Clara Silveira ${ }^{2}$
}

DOI: https://doi.org/10.31410/LIMEN.2020.179

\begin{abstract}
Information and Communication Technologies in the context of social organizations, enhance the definition of strategies to optimize the use of Information Systems in order to provide better support services to their users. The paper presents a real case of optimizing the current information system of a social organization in which it proposes to develop an integrative and multidisciplinary prototype incorporating sustainability concerns in the context of sustainable development objectives to improve cooperation between the Institution and its users. The methodology adopted was based on the literature review of the thematic and the case study. The main results point to the added value that a multidisciplinary and aggregator prototype can constitute in order to incorporate sustainability concerns in the technical, environmental, social, economic and individual fields.
\end{abstract}

Keywords: Sustainability, Information systems, Software development, Information and communication technologies.

\section{INTRODUCTION}

$\mathrm{C}$ urrently, most organizations are dependent on Information and Communication Technologies (ICT) in order to create added value to their business. In particular, social organisations are faced with the asset of specific challenges given the characteristics inherent to them. In this sense, it is advocated that the contribution of Information and Communication Technologies is of great interest to the implementation of strategies to support the activities of a social organization.

It is also considered that concerns in the field of social sustainability may go towards delineating a set of actions aimed at improving the quality of the provision of services to users of the Institution. These actions aim to reduce social inequalities, expand rights and ensure access to services, especially health and well-being.

For Balaman (Balaman, 2019), social sustainability includes the management of positive and negative impacts of systems, processes, organizations and activities on people and social life. This concept integrates, among many others, the topics of health and social equality, human and worker rights, justice, community development and well-being, community resilience and cultural competence.

The concept of social sustainability applies to the social organization of the case study to the extent that it integrates the multiple dimensions of sustainability: human, social, environmental, economic and technical, thus constituting multidimensional sustainability.

Polytechnic Institute of Setúbal, Portugal

Polytechnic Institute of Guarda, Portugal 


\section{BACKGROUND}

The Sustainable Development Goals (SDGs), also known as Global Goals, were adopted by all United Nations Member States in 2015 as a universal call to action to end poverty, protect the planet and ensure that everyone enjoys peace and prosperity by 2030 (UNDP, 2015).

Figure 1. SDG's - Agenda for Sustainable Development
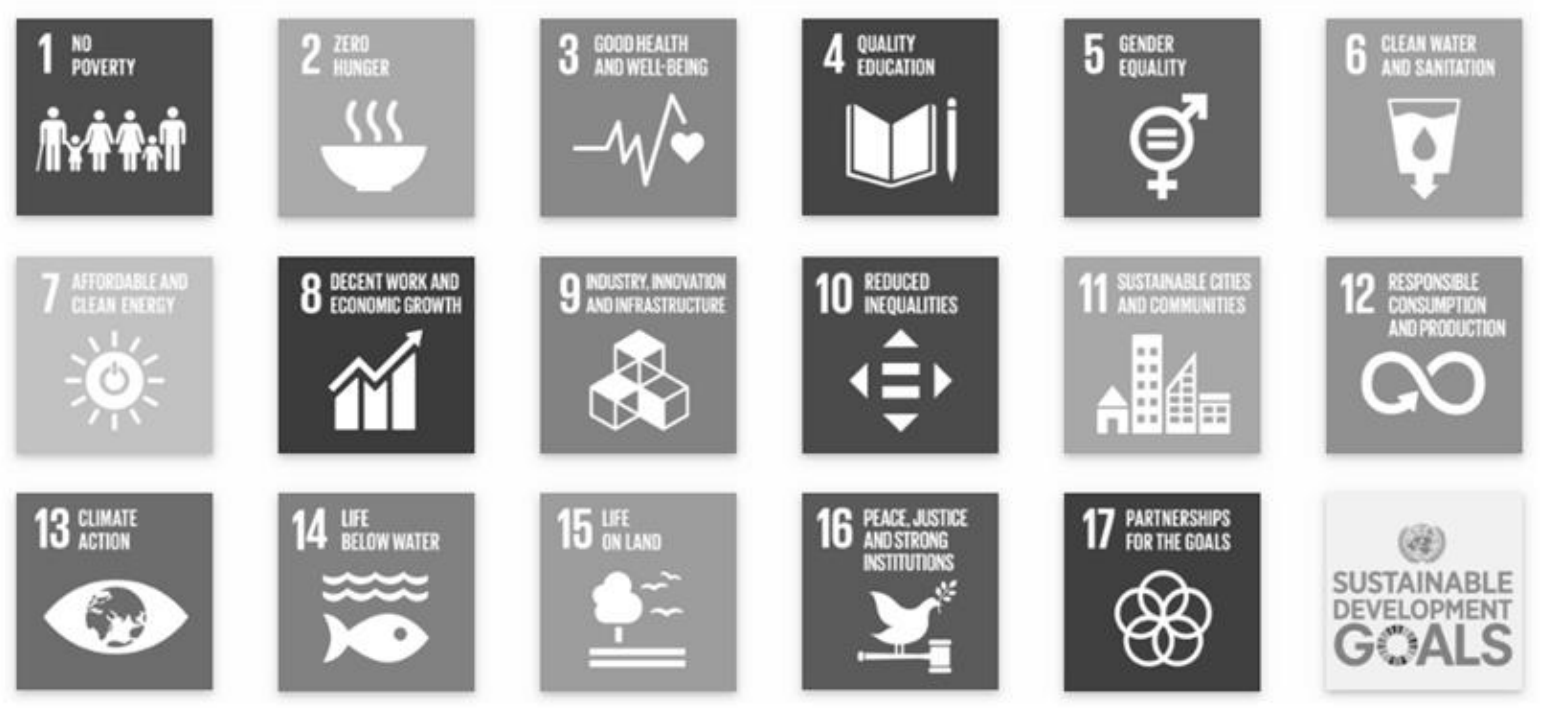

Source: (UNDP, 2015)

The 17 SDGs (Figure 1) are integrated as action in one area will affect results in others. The complex challenges we face today (for example, containing the spread of the pandemic) cannot be tackled in isolation. Therefore, integrated solutions require a common understanding of sustainable development.

The study of sustainability (Gianni, Gotzamani, \& Tsiotras, 2019; Hettrick, 2016; Meneses, 2019; Software Sustainability Institute, 2019; SustainAbility, 2018) in the various areas of knowledge is of the utmost importance. The research and applicability of sustainability software development and information systems is also critical. The software has made an invaluable contribution to the advancement of research (Software Sustainability Institute, 2019) by responding to the great challenges of our society. Good sustainability practices will enhance more sustainable and reusable software development. Software sustainability creates reliable, reproducible and reusable software (Hettrick, 2016).

In the research of (Becker, et al., 2015; Oyedeji, Ahmed, \& Penzenstadler, 2017; Penzenstadler, 2015), sustainability is multidimensional as it leads to the economic, social, environmental, technical and individual dimensions. Also in the perspective of these authors, the sustainability of the software is a principle and a commitment contained in the Manifesto de Karlskrona - Sustainability Design and Software. These principles are presented in Figure 2 . 
Figure 2. SDG's - Sustainability Principles - Karlskrona Manifesto
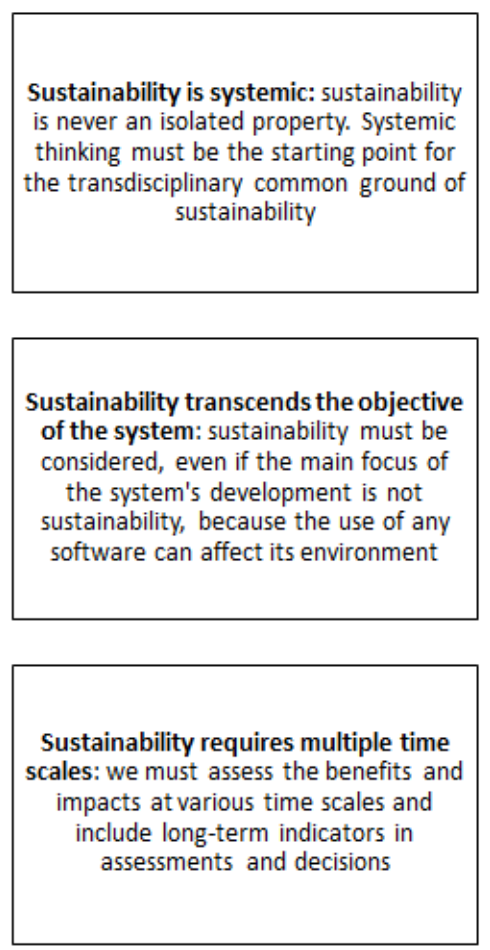
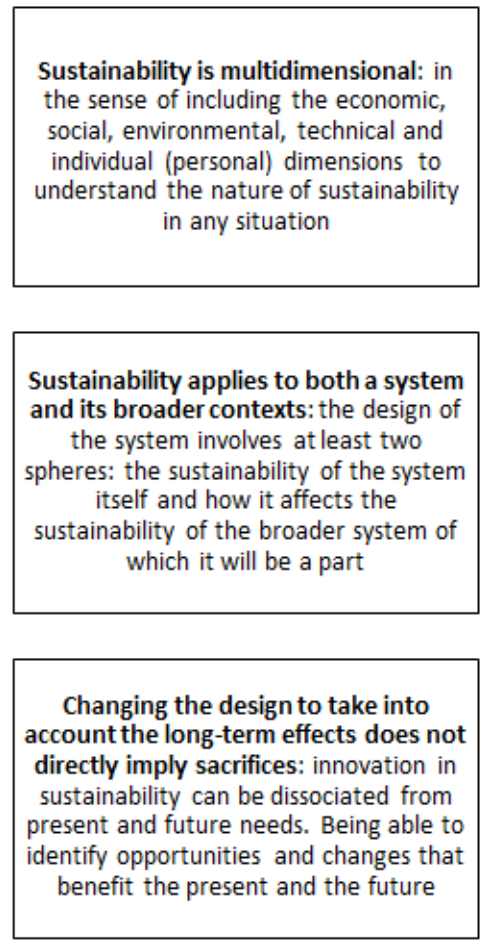

Sustainability is interdisciplinary: working in sustainability means working with people from different disciplines, addressing the challenges from different perspectives

Source: Adapted from (Becker et al., 2015)

Regarding these principles (Figure 2), it is intended to study the possible impact that sustainability concerns may contribute to the reflection on the current practices established in social organizations in this field of knowledge.

\section{CASE STUDY}

The case study, which is presented, aims to characterize the situation of the Community of São Domingos (CSD). The socio-cultural characterization of the Community was based on the need to optimize information system to support the activity of a social organization here called the Social Center.

The areas involved in studying the various valences supported by a comprehensive strategy were analyzed, namely: physical therapy, social situation, medical care, nursing care, housing, experience, skills, health, training, and volunteering (Silveira, Reis, Santos, \& Mamede, 2020b).

In order to integrate citizens, it is necessary to establish partnerships and involve official entities, such as: Public Security Police, Foreigners and Borders Service, Social Security, Parish Council, and Health Center.

To summarize all this information, Figure 3 was elaborated, which aims to show the areas involved in a multidisciplinary logic of support to the citizen of a community, which counts, by its nature, the commitment of the various official entities. 
Figure 3. CSD characterization in promoting SDG's

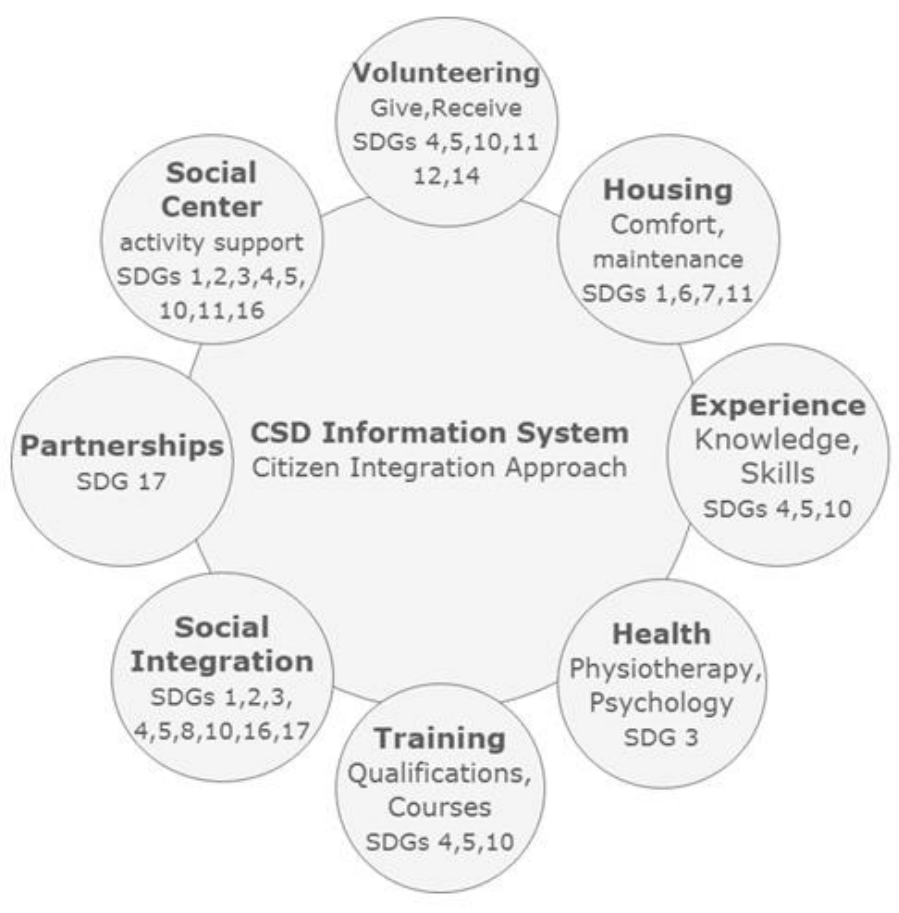

Source: (Silveira \& Reis, 2021)

Figure 3 allows the various entities involved in the process of creating synergies to optimize the provision of services to their users. It also shows the SDGs involved in each valence. In this way, sustainability is promoted in the community.

It should be noted that knowledge is creative and must be stimulated to develop (Davenport \& Prusak, 1998). In this way, technology is a mean to improve communication and collaboration between community elements, and experience/knowledge and skills can be shared (Silveira, Reis, Santos, \& Mamede, 2020a).

It is also intended to create a platform in which the various actors can, under their access profile, access the information of the elements of the CSD under analysis in order to optimize the services provided.

Based on the principles and commitments of the Karlskrona Manifesto (Becker et al., 2015), which provide an overview of the various dimensions of sustainability and its relationships, the corresponding scheme for CSD was built, it is thus intended to show the impact that sustainability concerns can have when optimizing an information system.

The application of the five dimensions of sustainability are described in Figure 4.

Figure 4 presents the various dimensions of sustainability, giving the various valences in the human, economic, environmental, technical and social fields that can be incorporated in view of the specificity of the case under study. 
Figure 4. Five dimensions of sustainability

\begin{abstract}
Human sustainability: information system designed to promote integration, overall health improvement for those receiving medical and nursing treatments. Improving individual sustainability is the focus of the system, allowing personal satisfaction in terms of health, comfort in housing, performance of volunteer tasks (give and receive)
\end{abstract}

Economic sustainability: reduction in energy costs, in consumer goods (donated and shared); volunteer services (housing maintenance, training, among others), reuse of non-perishable goods, among others

Environmental sustainability: reduction of carbon emissions and consumption of gasoline (transport sharing). Reuse of non-perishable goods, avoiding the waste of perishable goods (donation of goods)

Technical sustainability: the system will be available on a cloud platform, making it compatible with many mobile and desktop devices, without paying for licenses, and reducing the need for users of the application to stop using their older equipment

Social sustainability: community satisfaction due to social integration, welcoming, solving problems in housing; sharing resources and artifacts; community physical activity, biomechanics (monitoring); psychologist present (improved self-esteem)

\title{
FUTURE RESEARCH DIRECTIONS
}

Organizations feel the need to expand, improve their services and reduce response times to citizens, who are their customers (Landum, Reis \& Moura, 2020). Another aspect that also raises concerns is the domain of information security. In order to implement resilience and follow directives that encourage protection against disruptive incidents or events, Information Systems are increasingly prepared to resist failure, (Russo \& Reis, 2020). Open source platforms as well as the development of software free may be an added value in this area of work given the constraints of social organisations.

\section{CONCLUSION}

The optimization of the CSD SI was the basic objective of this Project. For its implementation, the literature was reviewed in this area, as well as including in this aspect of analysis concerns in the dimensions of sustainability, from the point of view: social, economic, technical, environmental and individual. With reference to these objectives, we studied the possible impact that the concerns raised in the various manifestos could contribute to the reflection on the current practices established in organizations in this field of knowledge.

The prototype, still under development, will enhance management practices, contributing to the optimization of the provision of services given the existence of several access profiles in order to allow the cooperation of several key areas in support of users. In view of the current state of the pandemic, teleworking can be a differentiating factor in the provision of social services of the institution with the increase of users in need of social support.

It is therefore considered that it was possible to assess that the implementation of sustainability concerns in an integrated aspect when optimising an IS and business support ICT can provide added value in order to contribute to the achievement of gains in various aspects.

As future work prospects, it is considered relevant to continue the analysis and strategy of optimizing policies in this field of knowledge. It is also intended to address the underlying concerns of information security, based on the specificity of the organization, service levels 
and access profiles, as the practices instituted to contribute to the availability of information and ubiquity can be optimized. It is also considered that paper dematerialisation can provide added value in process optimisation and thus contribute to sustainability.

\section{REFERENCES}

Becker, C., Chitchyan, R., Duboc, L., Easterbrook, S., Penzenstadler, B., Seyff, N., \& Venters, C. (2015). Sustainability Design and Software: The Karlskrona Manifesto, Proc. 37th International Conference on Software Engineering (ICSE 15).

Balaman, S. (2019). Sustainability Issues in Biomass-Based Production Chains. In Balaman, S. Decision-Making for Biomass-Based Production Chains, Academic Press. https://doi.org/10.1016/B978-0-12-814278-3.00004-2.

Gianni, M., Gotzamani, K., \& Tsiotras, G. (2019). Multiple perspectives on integrated management systems and corporate sustainability performance. Journal of Cleaner Production, 168, 1297-1311. doi:doi.org/10.1016/j.jclepro.2017.09.061.

Davenport, T., \& Prusak, L. (1998). Conhecimento Empresarial. Rio: Campus.

Hettrick, S. (2016). Research Software Sustainability: Report on a Knowledge Exchange Workshop; The Software Sustainability Institute.

Landum, M., Reis, L., \& Moura, M., (2020). Concept of approach to optimize ICT management practices - State of the art, in L. Cagica Carvalho, L. Reis, A. Prata, R. Pereira (eds), Handbook of Research on Multidisciplinary Approaches to Entrepreneurship, Innovation, and ICTs, USA: IGI Global, DOI: 10.4018/978-1-7998-4099-2.ch009.

Meneses, J. (2019). A sustentabilidade em 2019. Retrieved October 25, 2019, from BCSD Portugal: www.bcsdportugal.org/noticias/a-sustentabilidade-em-2019.

Oyedeji, S.; Ahmed, S., \& Penzenstadler, B. (2017). Sustainability Quantification in Requirements Informing Design; RE4SuSy2017.

Penzenstadler, B. (2015). Sustainability and Requirements: A Manifesto, IEEE Software; Volume: 32, Issue: 05, pp 90-92.

Russo N., \& Reis, L., (2020). Methodological approach to systematization of Business Continuity in organizations, in L. Cagica Carvalho, L. Reis, A. Prata, R. Pereira (eds), Handbook of Research on Multidisciplinary Approaches to Entrepreneurship, Innovation, and ICTs, USA: IGI Global, DOI: 10.4018/978-1-7998-4099-2.ch010.

Silveira, C., \& Reis, L. (2021). Sustainability in Information and Communication Technologies. In Carvalho, L. C., Reis, L., Prata, A., \& Pereira, R. (Ed.), Handbook of Research on Multidisciplinary Approaches to Entrepreneurship, Innovation, and ICTs (pp. 375-396). IGI Global. http://doi:10.4018/978-1-7998-4099-2.ch017.

Silveira, C., Reis, L., Santos, V. \& Mamede, H. (2020a). Criatividade no Design de Protótipos - O caso das Organizações Sociais. CISTI'2020 - 15th Iberian Conference on Information Systems and Technologies, Sevilha, Espanha, doi: 10.23919/CISTI49556.2020.9140870.

Silveira, C., Reis, L., Santos, V. \& Mamede, H. (2020b). Creativity in Prototypes Design and Sustainability - The case of Social Organizations, Advances in Science, Technology and Engineering Systems Journal, vol. 5, no. 6, pp. 1237-1243, doi: 10.25046/aj0506147.

Software Sustainability Institute. (2019). Manifesto. Retrieved from Software Sustainability Institute: www.software.ac.uk/about/manifesto.

SustainAbility. (2018). Sustainability: Can our society endure? Retrieved September 25, 2019, from: SustainAbility an ERM Group company: //sustainability.com/sustainability/.

UNDP (2015). Sustainable Development Goals, Retrieved September 30, 2019, from United Nations Development Programme: www.undp.org/content/undp/en/home/sustainabledevelopment-goals.html. 